\title{
Nonlinear Differential Equation of Macroeconomic Dynamics for Long-Term Forecasting of Economic Development
}

\author{
Askar Akaev \\ Prigogine Institute of Mathematical Investigations of Complex Systems, Moscow State University, Moscow, Russia \\ Email: askarakaev@mail.ru
}

How to cite this paper: Akaev, A. (2018) Nonlinear Differential Equation of Macroeconomic Dynamics for Long-Term Forecasting of Economic Development. Applied Mathematics, 9, 512-535. https://doi.org/10.4236/am.2018.95037

Received: March 20, 2018

Accepted: May 27, 2018

Published: May 30, 2018

Copyright $\odot 2018$ by author and Scientific Research Publishing Inc. This work is licensed under the Creative Commons Attribution International License (CC BY 4.0).

http://creativecommons.org/licenses/by/4.0/

\section{c) (i) Open Access}

\begin{abstract}
In this article we derive a general differential equation that describes long-term economic growth in terms of cyclical and trend components. Equation is based on the model of non-linear accelerator of induced investment. A scheme is proposed for obtaining approximate solutions of nonlinear differential equation by splitting solution into the rapidly oscillating business cycles and slowly varying trend using Krylov-Bogoliubov-Mitropolsky averaging. Simplest modes of the economic system are described. Characteristics of the bifurcation point are found and bifurcation phenomenon is interpreted as loss of stability making the economic system available to structural change and accepting innovations. System being in a nonequilibrium state has a dynamics with self-sustained undamped oscillations. The model is verified with economic development of the US during the fifth Kondratieff cycle (1982-2010). Model adequately describes real process of economic growth in both quantitative and qualitative aspects. It is one of major results that the model gives a rough estimation of critical points of system stability loss and falling into a crisis recession. The model is used to forecast the macroeconomic dynamics of the US during the sixth Kondratieff cycle (2018-2050). For this forecast we use fixed production capital functional dependence on a long-term Kondratieff cycle and medium-term Juglar and Kuznets cycles. More accurate estimations of the time of crisis and recession are based on the model of accelerating log-periodic oscillations. The explosive growth of the prices of highly liquid commodities such as gold and oil is taken as real predictors of the global financial crisis. The second wave of crisis is expected to come in June 2011.
\end{abstract}

\section{Keywords}

Long-Term Economic Trend, Cycles, Nonlinear Accelerator, Induced and 
Autonomous Investment, Differential Equations of Macroeconomic Dynamics, Bifurcation, Stability, Crisis Recession, Forecasting, Explosive Growth in the Prices of Highly Liquid Commodities as a Predictor of Crisis

\section{Introduction}

Economy usually fluctuates around its trend path. These fluctuations are cyclical, but irregular. Trend is the result of the factors responsible for long-term growth of the economy, such as capital inflows, manpower increase, scientific and technical progress. Business cycles represent deviations of the real aggregate output from its long-term trend caused by distributed in time random supply shocks. In 1950s there were developed some elegant mathematical models of the theory of cycles based on the mechanism of interaction between the multiplier and accelerator [1], as well as neoclassical growth theories using the production functions [2]. They became the starting point for all subsequent research in these two central issues of macroeconomic dynamics. The main drawback of these models was an isolated consideration of growth and cyclical fluctuations, whereas the Schumpeterian theory of economic development [3] [4] states that cyclical fluctuations are an integral part of sustainable economic growth. Therefore, the theory of real business cycles (RBC) must necessarily include the interaction of the mechanisms of growth and cyclical fluctuations. The tenets of the discrete RBC theory were laid in the 1980s by Nobel laureates F. Kydland and E. Prescott [5]. They developed an RBC model based on stochastic dynamic model of general equilibrium. Their model included a stochastic version of the neoclassical Solow's growth model [2]. Kydland's and Prescott's discrete RBC model became the basic one in macroeconomic computer simulation.

\section{Derivation of the Macroeconomic Dynamics Equation Describing the Interaction of Long-Term Growth and Business Cycles}

Our first attempt to create a continuous RBC model was described in [6]. This is a general differential equation of macroeconomic dynamics based on the interaction of the mechanisms of growth and cyclical fluctuations. Let us start deriving this equation following the most fruitful scheme formerly chosen by Phillips [1]. In this scheme it is assumed that the planned values for consumption and investment are achieved. We also take this starting point. Hence consumption and investment plans (with a certain lag) turn into actual costs, which give a total output. If you select the expenditures (independent from revenue) $A$ on capital investment and consumption, the basic equilibrium condition is written as

$$
Y=C+I+A,
$$

where $C$ is consumption; $I$ is actual induced investment. 
Since $I$ represents the actual induced investment at time $t$ caused by changes in yield and the lag in the form of an exponential function, $I$ satisfies the delay differential equation:

$$
\frac{\mathrm{d} I}{\mathrm{~d} t}=-æ[I(t)-J(t)]
$$

where $J(t)$ is potential capital investment; $æ$ is lag reaction rate, while time lag constant is $T=1 /$ æ. The volume of investments $\mathcal{J}(t)$ and the current rate of yield change are connected in general via nonlinear accelerator $J(t)=\psi\left\{v \frac{\mathrm{d} Y}{\mathrm{~d} t}\right\}[1]$ where $v$ is power of the accelerator $(v>0)$. Goodwin has shown [1] that the most appropriate function for the nonlinear accelerator is the logistic function. Consequently, we have

$$
J(t)=\frac{1}{2} t h\left(\frac{k v}{2} \frac{\mathrm{d} Y}{\mathrm{~d} t}\right) \cong \frac{1}{2}\left[\frac{k v}{2} \frac{\mathrm{d} Y}{\mathrm{~d} t}-\frac{1}{3}\left(\frac{k v}{2} \frac{\mathrm{d} Y}{\mathrm{~d} t}\right)^{3}\right] .
$$

Here we have taken first two terms of power series, which is a good approximation within the condition $\left|\frac{k v}{2} \frac{\mathrm{d} Y}{\mathrm{~d} t}\right|<\frac{\pi}{2}$ that is always true for real values of $v$ and $\frac{\mathrm{d} Y}{\mathrm{~d} t}$. Since for small values of $\left|\frac{\mathrm{d} Y}{\mathrm{~d} t}\right|$ there occurs the simplest or linear accelerator $J(t)=v \frac{\mathrm{d} Y}{\mathrm{~d} t}$, then (3) directly implies that $k=4$. Thus we use the following approximation for the nonlinear accelerator according to Goodwin:

$$
J(t) \cong\left[1-\frac{4}{3}\left(v \frac{\mathrm{d} Y}{\mathrm{~d} t}\right)^{2}\right] v \frac{\mathrm{d} Y}{\mathrm{~d} t}
$$

We return to the basic equilibrium condition (1). Since demand lags are absent, and planned consumption is $C=c Y=(1-s) Y$, where $c$ and $s$ are the coefficients of consumption and savings, aggregate demand will be equal to

$$
Z=(1-s) Y+I+A \text {. }
$$

Supply is also taken with a continuously distributed lag of the exponential form and the reaction rate $\lambda$ :

$$
\frac{\mathrm{d} Y}{\mathrm{~d} t}=-\lambda(Y-Z) .
$$

Equations ((2), (5) and (6)) are the model equations for a real economic system. In order to obtain a differential equation for the yield of $Y$ it is necessary to eliminate $Z$ and $I$ from the model equations. For this purpose we first substitute (5) for (6), noting that in (5) we have potential or expected $\left(Y^{e}, I^{e}\right)$ variable values, i.e. $Z=(1-s) Y^{e}+I^{e}+A^{e}$. However, $A^{e}=A$ as independent investment, while $I^{e}=I$ accords to the accepted premise of the model. Hence we have

$$
\frac{\mathrm{d} Y}{\mathrm{~d} t}=-\lambda\left[Y-(1-s) Y^{e}-I-A\right]
$$


Solving the last equation for $I$ and differentiating the resulting expression we obtain, respectively:

$$
\begin{gathered}
I=\frac{1}{\lambda} \frac{\mathrm{d} Y}{\mathrm{~d} t}+Y-(1-s) Y^{e}-A \\
\frac{\mathrm{d} I}{\mathrm{~d} t}=\frac{1}{\lambda} \frac{\mathrm{d}^{2} Y}{\mathrm{~d} t^{2}}+\frac{\mathrm{d} Y}{\mathrm{~d} t}-(1-s) \frac{\mathrm{d} Y^{e}}{\mathrm{~d} t}-\frac{\mathrm{d} Y A}{\mathrm{~d} t} .
\end{gathered}
$$

Substituting these expressions into Equation (2) we obtain the following differential equation for the yield $Y$ :

$$
\begin{gathered}
\frac{\mathrm{d}^{2} Y}{\mathrm{~d} t^{2}}+\{\lambda+ \\
\left.+æ-æ \lambda v\left[1-\chi \frac{4}{3}\left(v \frac{\mathrm{d} Y}{\mathrm{~d} t}\right)^{2}\right]\right\} \frac{\mathrm{d} Y}{\mathrm{~d} t}-\lambda(1-s) \frac{\mathrm{d} Y^{e}}{\mathrm{~d} t} \\
+æ \lambda Y-æ \lambda(1-s) Y^{e}=\lambda \frac{\mathrm{d} A}{\mathrm{~d} t}+æ \lambda A
\end{gathered}
$$

Here constant $\chi$ takes only two values, 0 or 1 . At $\chi=0$ we have the classic Phillips model with a linear accelerator, and if $\chi=1$ we have the Phillips-Goodwin model with nonlinear accelerator [1].

If in Equation (7) we assume $Y=Y^{e}$, which is a very rough approximation, since yield $Y$ is an unplanned value, and if we set $\chi=0$ and $A=$ const as well, then we come to the well-known equation of Phillips [1]:

$$
\frac{\mathrm{d}^{2} Y}{\mathrm{~d} t^{2}}+(\lambda s+æ-æ \lambda v) \frac{\mathrm{d} Y}{\mathrm{~d} t}+æ \lambda s Y=æ \lambda A .
$$

Unlike Phillips and Goodwin, we will include into (7) an expression for the potential (expected) value of yield $Y^{e}$ defined by the basic factors of production, i.e. capital $(K)$ and labor $(L)$. As it is well known [2], the connection of yield with factors of production is determined by the production function of the form $\bar{Y}=F(K, L)$, which represents the trajectory of long-term economic growth. Since the production functions possess the homogeneity property, they satisfy Euler's equation [7]:

$$
a K \frac{\partial \bar{Y}}{\partial K}+b L \frac{\partial \bar{Y}}{\partial L}=h \bar{Y},
$$

where $a, b$ and $h$ are constant coefficients. This implies the desired approximate expression for the expected value of $Y^{e}$ yield:

$$
Y^{e} \cong \bar{Y}=\frac{a}{h} K \frac{\partial \bar{Y}}{\partial K}+\frac{b}{h} L \frac{\partial \bar{Y}}{\partial L} .
$$

It is obvious that this approximation is more accurate than the very rough Phillips's assumption $Y=Y^{e}$. But the main advantage of this approach is that it provides an opportunity to introduce production factors into the basic equation. Differentiating (8) on time and performing the necessary simplification, we obtain:

$$
\frac{\mathrm{d} Y^{e}}{\mathrm{~d} t} \cong \frac{\partial \bar{Y}}{\partial K} \frac{\mathrm{d} K}{\mathrm{~d} t}+\frac{\partial \bar{Y}}{\partial L} \frac{\mathrm{d} L}{\mathrm{~d} t}
$$


It is necessary to exclude $\frac{\mathrm{d} L}{\mathrm{~d} t}$ from here. For this we use the Okun's law [8] establishing the relationship between change in unemployment rate $\left(u-u^{*}\right)$ and change in yield $\left(Y_{F}-Y\right)$ :

$$
\frac{Y_{F}-Y}{Y_{F}}=\gamma\left(u-u^{*}\right) .
$$

Here $\gamma$ is Okun's parameter $(\gamma=2 \div 3) ; Y_{F}\left(L^{*}\right)$ is the national income at full employment, $Y(L)$ is the actual yield in the presence of market unemployment; $L^{*}$ is the number of workers at full employment; $L$ is the actual number of workers employed in production; $u^{*}$ is the natural rate of unemployment corresponding to full employment $L^{*} ; u$ is the actual level of unemployment. As $u-u^{*}=\frac{L^{*}-L}{L^{*}}$, then from (10) it follows that $Y_{F}-Y=\gamma^{*}\left(L^{*}-L\right)$, where $\gamma^{*}=\gamma \frac{Y_{F}}{L^{*}}$. Differentiating both sides of this relation, we obtain the required expression:

$$
\frac{\mathrm{d} L}{\mathrm{~d} t}=\frac{1}{\gamma^{*}} \frac{\mathrm{d} Y}{\mathrm{~d} t} .
$$

As is known, the average labor productivity $\left(\frac{Y_{K}}{L^{*}}\right)$ is associated with extreme (marginal) labor productivity $\left(\frac{\partial \bar{Y}}{\partial L}\right)$ as follows [9]: $\frac{\partial \bar{Y}}{\partial L} \cong \beta \frac{Y_{F}}{L^{*}}$. Therefore,

$$
\gamma^{*}=\frac{\gamma}{\beta} \frac{\partial \bar{Y}}{\partial L}
$$

Substituting (11) and (12) into the initial expression (9), we obtain:

$$
\frac{\mathrm{d} Y^{e}}{\mathrm{~d} t}=\frac{\partial \bar{Y}}{\partial K} \frac{\mathrm{d} K}{\mathrm{~d} t}+\frac{\beta}{\gamma} \frac{\mathrm{d} Y}{\mathrm{~d} t} .
$$

Now it remains to substitute $Y^{e}$ (8) and $\frac{\mathrm{d} Y^{e}}{\mathrm{~d} t}$ (13) into Equation (7). As a result, we obtain the desired total differential equation of macroeconomic dynamics:

$$
\begin{aligned}
& \frac{\mathrm{d}^{2} Y}{\mathrm{~d} t^{2}}+\left[\lambda+æ-æ \lambda \nu-\lambda(1-s) \frac{\beta}{\gamma}+\chi \frac{4}{3} æ \lambda v\left(v \frac{\mathrm{d} Y}{\mathrm{~d} t}\right)^{2}\right] \frac{\mathrm{d} Y}{\mathrm{~d} t} \\
& +æ \lambda Y-æ \lambda(1-s) \bar{Y}-\lambda(1-s) \frac{\partial \bar{Y}}{\partial K} \frac{\mathrm{d} K}{\mathrm{~d} t}=\lambda\left(\frac{\mathrm{d} A}{\mathrm{~d} t}+æ A\right)
\end{aligned}
$$

Under suitable initial and boundary conditions the Equation (14) allows finding the flow of yield. This equation takes into account the law of capital accumulation, as well as the Okun law establishing a connection between the fluctuations in unemployment and yield fluctuations. Some of coefficients may be random variables. The right side of the equation usually contains a random component. Therefore in general Equation (14) we find a stochastic differential equ- 
ation, combining deterministic and stochastic approaches of the study of real business cycles. In this equation, we are dealing with two variables that characterize the yield: the rapidly changing variable $Y(t)$, which contains the cyclical fluctuations $y=Y-\bar{Y}$, and slowly varying $\bar{Y}(t)$, representing the trend curve. This circumstance makes it possible to separate them using Krylov-Bogoliubov-Mitropolsky averaging [10]. Indeed, we can first average the rapidly changing variable $y(t)$ and get a simplified description of the system dynamics-long-term trend described by $\bar{Y}(t)$. This approach makes it relatively easy to find both dependences.

For further analysis of Equation (14) it is important to distinguish the trend component in its right side, which is determined by the investments independent from income. This includes the investment of public and private organizations into the development of public infrastructure, and investment caused by scientific and technological progress, inventions and technological innovations that not only define the long-term growth, but also affect the short-term fluctuations, since they are irregular. It also includes independent expenditures on household consumption. Thus, the independent investment $A(t)$ can always be represented as $A(t)=\bar{A}(t)+\varphi(t)$, where $\bar{A}(t)$ is trend component (e.g., $\left.\bar{A}(t)=A_{0} \mathrm{e}^{g t}\right) ; \varphi(t)$ is quasi-periodic function oscillating around the trend component. Thus, the right side of the equation becomes:

$$
\frac{\mathrm{d} A}{\mathrm{~d} t}+\mathfrak{x} A=\left(\frac{\mathrm{d} \bar{A}}{\mathrm{~d} t}+\mathfrak{} \bar{A}\right)+\left(\frac{\mathrm{d} \varphi}{\mathrm{d} t}+æ \varphi\right) .
$$

The second term on the right side of this expression has a direct influence on cyclical fluctuations.

First of all, we distinguish in the basic Equation (14) the cyclical fluctuations described by the variable $y=Y-\bar{Y}$. For this, first, the nonlinear term $\left(v \frac{\mathrm{d} Y}{\mathrm{~d} t}\right)^{2}$ will replace with approximation $\left(v \frac{\mathrm{d} y}{\mathrm{~d} t}\right)^{2}$ to use the principle of superposition, because $\bar{Y}$ is a slowly varying function in comparison with $Y$ or $y$. Moreover, this nonlinear term is retained only with $y(\chi=1)$ and lacks with $\bar{Y}(\chi=0)$. Substituting $Y=y+\bar{Y}$ into the Equation (14) we obtain:

$$
\begin{aligned}
& \frac{\mathrm{d}^{2} y}{\mathrm{~d} t^{2}}+\sigma \frac{\mathrm{d} y}{\mathrm{~d} t}+\omega^{2} y+\frac{\mathrm{d}^{2} \bar{Y}}{\mathrm{~d} t^{2}}+\bar{\sigma} \frac{\mathrm{d} \bar{Y}}{\mathrm{~d} t}+\bar{\omega}^{2} \bar{Y}-\lambda(1-s) \frac{\partial \bar{Y}}{\partial K} \frac{\mathrm{d} K}{\mathrm{~d} t} \\
& =\lambda\left(\frac{\mathrm{d} \bar{A}}{\mathrm{~d} t}+\mathfrak{x}\right)+\lambda\left(\frac{\mathrm{d} \varphi}{\mathrm{d} t}+æ \varphi\right) .
\end{aligned}
$$

Here

$$
\begin{gathered}
\sigma=\lambda+\mathfrak{x}-(1-\mathrm{s}) \lambda \frac{\beta}{\gamma}-\mathfrak{x} \lambda v\left[1-\frac{4}{3}\left(v \frac{\mathrm{d} y}{\mathrm{~d} t}\right)^{2}\right] ; \quad \omega^{2}=\lambda \mathfrak{x} ; \\
\bar{\omega}^{2}=\lambda \mathfrak{x} ; \quad \bar{\sigma}=\lambda+\mathfrak{x}-\mathfrak{x} \lambda v-(1-s) \lambda \frac{\beta}{\gamma} .
\end{gathered}
$$

As $\frac{\partial \bar{Y}}{\partial L}$ and $\frac{\partial \bar{Y}}{\partial K}$ are both slowly varying functions they can be replaced by 
the expressions obtained from profit maximization within the model of perfect competition [7]:

$$
\frac{\partial \bar{Y}}{\partial K}=i ; \frac{\partial \bar{Y}}{\partial L}=w \cong \beta \frac{Y_{F}}{L^{*}},
$$

where the $i$ is rate of interest; $w$ is real wages; $\beta$ reflects the elasticity of output to labor in the Cobb-Douglas production function. We have already used earlier the second of these relations. Therefore Equation (16) has the form:

$$
\begin{aligned}
& \frac{\mathrm{d}^{2} y}{\mathrm{~d} t^{2}}+\delta \frac{\mathrm{d} y}{\mathrm{~d} t}+\omega^{2} y+\frac{\mathrm{d}^{2} \bar{Y}}{\mathrm{~d} t^{2}}+\bar{\delta} \frac{\mathrm{d} \bar{Y}}{\mathrm{~d} t}+\bar{\omega}^{2} \bar{Y} \\
& =\lambda\left(\frac{\mathrm{d} \bar{A}}{\mathrm{~d} t}+æ \bar{A}\right)+\lambda\left(\frac{\mathrm{d} \varphi}{\mathrm{d} t}+æ \varphi\right)+\lambda(1-s) i \frac{\mathrm{d} K}{\mathrm{~d} t} .
\end{aligned}
$$

At the next step we use averaging on (18) for rapidly changing variables $y$ and $\varphi$ and get a simplified differential equation that describes only its trend trajectory:

$$
\frac{\mathrm{d}^{2} \bar{Y}}{\mathrm{~d} t^{2}}+\bar{\sigma} \frac{\mathrm{d} \bar{Y}}{\mathrm{~d} t}+\bar{\omega}^{2} \bar{Y}=\lambda\left(\frac{\mathrm{d} \bar{A}}{\mathrm{~d} t}+æ \mathrm{~A}\right)+\lambda(1-s) i \frac{\mathrm{d} K}{\mathrm{~d} t}=F_{1}(t)
$$

Initial conditions are as follows:

$$
\bar{Y}_{\mid t=T_{0}}=\bar{Y}_{0} ; \frac{\mathrm{d} \bar{Y}}{\mathrm{~d} t}_{\mid t=T_{0}}=x_{0} .
$$

The principle of averaging leads to the equation $\frac{\mathrm{d}^{2} y}{\mathrm{~d} t^{2}}+\sigma \frac{\mathrm{d} y}{\mathrm{~d} t}+\omega^{2} y=\lambda\left(\frac{\mathrm{d} \varphi}{\mathrm{d} t}+\mathfrak{x} \varphi\right)$ describing the cyclical fluctuations. In this equation we must take into account the nonlinearity of the accelerator comprised in the coefficient $\sigma(17)$. Therefore, we will analyze the solution of the nonlinear differential equation in the form:

$$
\frac{\mathrm{d}^{2} y}{\mathrm{~d} t^{2}}-\left[\sigma_{0}-\frac{4}{3} æ \lambda v^{3}\left(\frac{\mathrm{d} y}{\mathrm{~d} t}\right)^{2}\right] \frac{\mathrm{d} y}{\mathrm{~d} t}+\omega^{2} y=F_{2}(t),
$$

where $\sigma_{0}=-\left[\lambda+\mathfrak{x}-\mathfrak{x} \lambda v-\lambda(1-s) \frac{\beta}{\gamma}\right] ; \omega^{2}=\lambda \mathfrak{x} ; \beta=\frac{h}{b}-a$.

The resulting equation is widely known as the Rayleigh equation, which is of great importance in the theory of oscillations.

Equation (21) includes a non-linear accelerator investment equal to $\frac{4}{3} k \lambda\left(v \frac{\mathrm{d} y}{\mathrm{~d} t}\right)^{3}$, which provides maintenance of the persistent cyclical fluctuations in economic system. Economic system with nonlinear accelerator is a classic self-oscillating system in which the role of positive feedback mechanism is played by non-linear accelerator, and the power of the accelerator $v$ is the gain. If the gain is large enough $(v>1.05)$, self-sustaining oscillations appear in the system, whose characteristics are determined by internal (structural) system parameters [11]. Thus, at $v=1.05$ there is a bifurcation of the cycle in the system. In deriving Equation (21) the cyclical unemployment was also taken into ac- 
count, which occurs in periods of recession, allowing us to consider the real economy with underemployment. It is known that fluctuations in unemployment are associated with fluctuations in actual yield according to Okun law [8].

We have already noted that the power of the accelerator is a control parameter and has a decisive influence on the dynamics of the economic system, the formation of long-term growth trajectory. Since the power of the accelerator is proportional to the business activity, while the latter is determined by economic conditions in the first approximation, we can assume that it is changing slowly, a sinusoidal, in sync with large Kondratieff cycle, i.e.:

$$
v=v_{0}-\frac{v_{1}}{2} \sin \psi t, v \geq 0
$$

As the duration of the fifth Kondratieff cycle is 35 years [12], we can take $\psi=\frac{2}{11} \quad(T=11 \pi \approx 34.5$ years $)$. The range of practical changes in the accelerator power is $0<v<2$ [11], so it is expedient that $v_{0} \geq 1.0$. In further calculations we take $v_{0}=1.1$.

\section{Examples of modeling modes of economic system development}

Linear differential Equation (19) with constant coefficients can be integrated in analytical form. For a nonlinear differential Equation (21), in the case of weak nonlinearity, the accelerator (for small power of accelerator) can also obtain an approximate solution in explicit analytical form using the averaging method by Krylov-Bogolyubov-Mitropolsky. These cases are considered in detail in [13]. We give three specific examples.

The first example illustrates the natural oscillations of the economic system. External influence is absent, i.e. $\varphi^{*}=0$. Assume that the trajectory of the trend is exponential. Then, solving Equation (21) by averaging, we obtain cyclical fluctuations $y_{c m}=y_{0} \cos (\omega t+\vartheta)$. Then, by superposition of the trend and cyclical fluctuations of the trajectory, we obtain very simple approximate formula for describing the steady-state issue:

$$
Y_{c m}=\mathrm{e}^{p t}+y_{0} \cos (\omega t+\vartheta), \quad y_{0}=\sqrt{\frac{\sigma_{0}}{\sigma_{1}}},
$$

where $\sigma_{1}=æ \lambda v^{3} \omega^{2} ; p$ is trend growth rate. The graph of the corresponding trajectory of economic development is presented in Figure 1.

The second example shows the effect of external periodic perturbations. Assume that $\varphi^{*}=q \sin v t$. In this case, the superposition of solutions of Equations ((19) and (21)) has the form:

$$
Y_{c m}=\mathrm{e}^{p t}+\sigma_{3} \cos (\omega t+\vartheta)+\frac{q}{\omega^{2}-v^{2}} \sin v t
$$

where $\sigma_{3}=\frac{4 \sigma_{0}-6 \sigma_{2}(v U)^{2}}{3 \sigma_{2} \omega^{2}} ; \sigma_{2}=\frac{4}{3} \mathfrak{x} \lambda v^{3} ; \quad U=\frac{q}{\omega^{2}-v^{2}}$.

Trajectory of the issue (24) is shown in Figure 2.

The third example illustrates the effect on the autonomous system of the sta- 
tionary "white noise" $\sigma_{\xi} \xi(t)$, where $\xi(t)$ is Gaussian white noise; $\sigma_{\xi}$ is the standard deviation. One of the many stochastic trajectories of output is shown in Figure 3.

Qualitative analysis of oscillations' influencing economic growth

In [11] a qualitative analysis is given of solutions of differential Equations ((19)

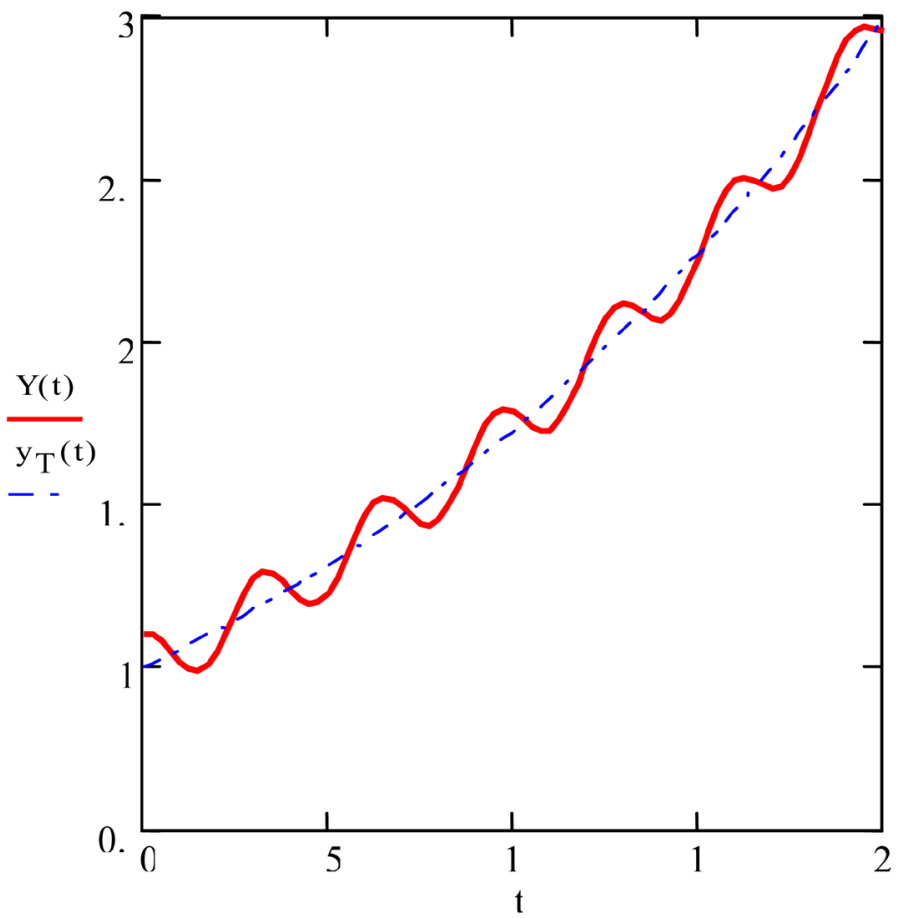

Figure 1. Natural oscillations of the economic system.

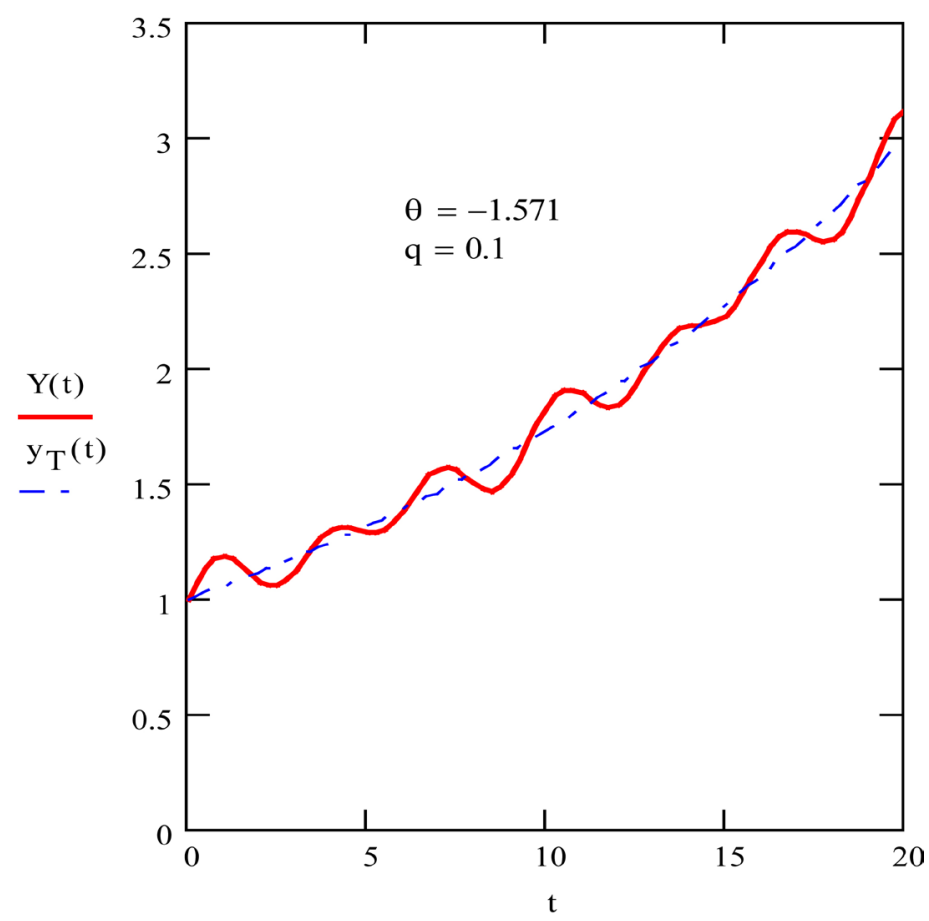

Figure 2. Forced oscillations of the economic system. 


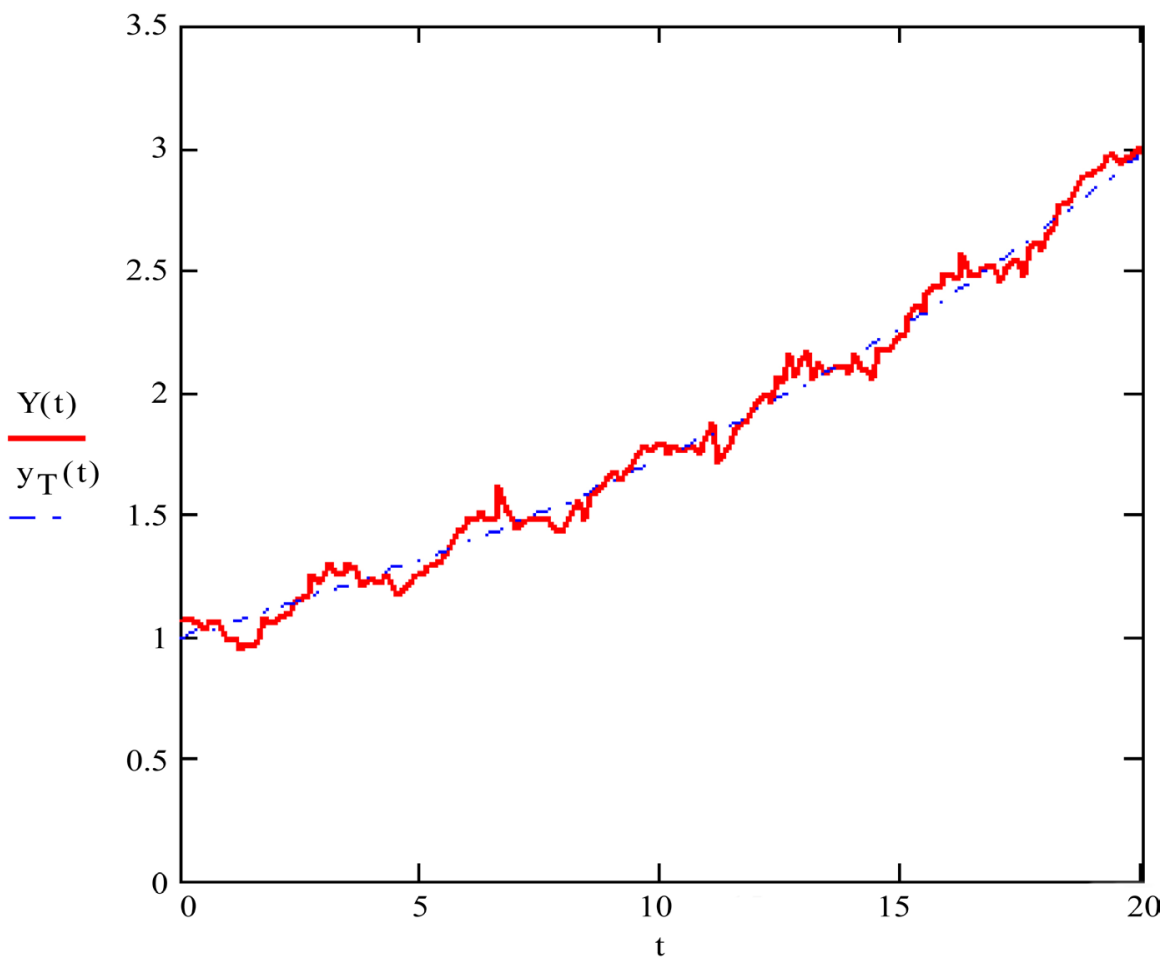

Figure 3. The impact of the stationary "white noise" on the economic system with $\sigma=$ $0.05\left(a_{m}=0.084, \sigma_{a}=0.046, \sigma_{\theta}=0.213\right)$.

and (21)) describing the cyclical fluctuations in business activity and economic growth, the stability of the system is viewed, the bifurcation point is calculated $\left(v_{1}=1.05\right)$ where the system loses stability and becomes receptive to structural change and innovation. It is shown that the consequence of a bifurcation is the emergence of a self-sustaining system of undamped oscillations. It is in conditions of disequilibrium that a change of level of balance occurs, causing increasing economic growth. Also the mechanism of influence of cyclical fluctuations on the formation of the trajectory of long-term economic growth has been investigated.

1) Sustainable long-term economic growth in the dynamic model (19)-(21) is guaranteed within the accelerator power range $0<v<\frac{\lambda+\mathfrak{x}}{\lambda \mathfrak{x}},(0<v<1.25)$. Moreover, at values $v<\frac{1}{\lambda \mathfrak{x}}\left[\lambda+\mathfrak{x}-\lambda(1-s) \frac{B}{\gamma}\right], \quad(v<1.05)$, any external shock effects are smoothed out by the system and, the system, being withdrawn from the equilibrium state, asymptotically tends to a stable initial trend of economic growth.

In the range of values $\frac{1}{\lambda \mathfrak{x}}\left[\lambda+\mathfrak{x}-\lambda(1-s) \frac{\beta}{\gamma}\right]<v<\frac{\lambda+\mathfrak{x}}{\lambda \mathfrak{x}}$, the equilibrium state is unstable; a bifurcation occurs in the system and a stable undamped oscillatory regime is produced. This regime is good because it favors structural changes necessary for processing and mastering of innovations. The economic system itself passes to a new equilibrium state, which is fixed by the au- 
to-oscillation that has arisen in the system, i.e. the trend of long-term growth shifts in most cases to a higher level, providing an increase in growth rates. Consequently, the regime of self-oscillations in the economic system is extremely useful, as it facilitates the structural transformations required to perceive innovation, and also provides stability to development and a change in equilibrium levels, which in turn determines the stepped trajectory of long-term economic growth.

2) At high values of accelerator $v>\frac{\lambda+\mathfrak{x}}{\lambda \mathfrak{r}},(v>2.05)$ economic growth can become unstable due to the explosive nature of the influence of cyclical fluctuations of the system. However, due to the cyclical nature of $v$, and the natural restriction of output caused by the drop in entrepreneurial profit, the subsequent decline in production before the onset of a new level of equilibrium fixed with a decrease in the power of the accelerator, the system will continue a relatively stable growth, alternating equilibrium levels and staying between them in a nonequilibrium state, i.e., in a state of dynamic equilibrium.

3) Self-oscillations are characteristic for developed economies with high entrepreneurial activity and innovative susceptibility, therefore the economies of developed countries are relatively stable. In countries where entrepreneurial activity is low, auto-oscillations in the economy are virtually excluded, there can only be forced fluctuations caused by exogenous shocks. Since the amplitude of self-oscillations of the system does not depend on the initial conditions and is determined only by the internal structural parameters of the system and it is minimal, and the self-oscillations themselves play a decisive role in accelerating the rates of economic growth and giving stability to development, then measures are necessary that contribute to the formation and maintenance of short-term auto-oscillation which is achieved by encouraging and supporting the innovative activity of entrepreneurs.

All this is well illustrated by the phase portrait shown in Figure 4.

In general, when the coefficients of differential Equations ((19) and (21)) are slow changing variables and the nonlinearity accelerator is high, then, for the solution of these equations it is necessary to use numerical methods and computer simulation exercise. In this case the right accelerator's functional dependence on time is of high priority.

In [14] there is a description of computer simulation of the economic system (19) and (21) with complicated periodical external disturbance and variable power accelerator for different values of power close to critical. The results are shown in Figure 5. As is evident from considering the graph, for certain values of power $\left(v_{0}=1 ; v_{1}=1.05\right)$ a loss of stability occurs in the system and the economy gets into crisis, falling into a deep recession. Importantly, the loss of stability is associated with breaking the trend of the curve, but not cyclical fluctuations. This corresponds to the assertion of Schumpeter that the equilibrium trajectory is steep and cyclical component has a form of wave. GDP dynamics presented in Figure 5 shows that the mathematical model quite adequately 


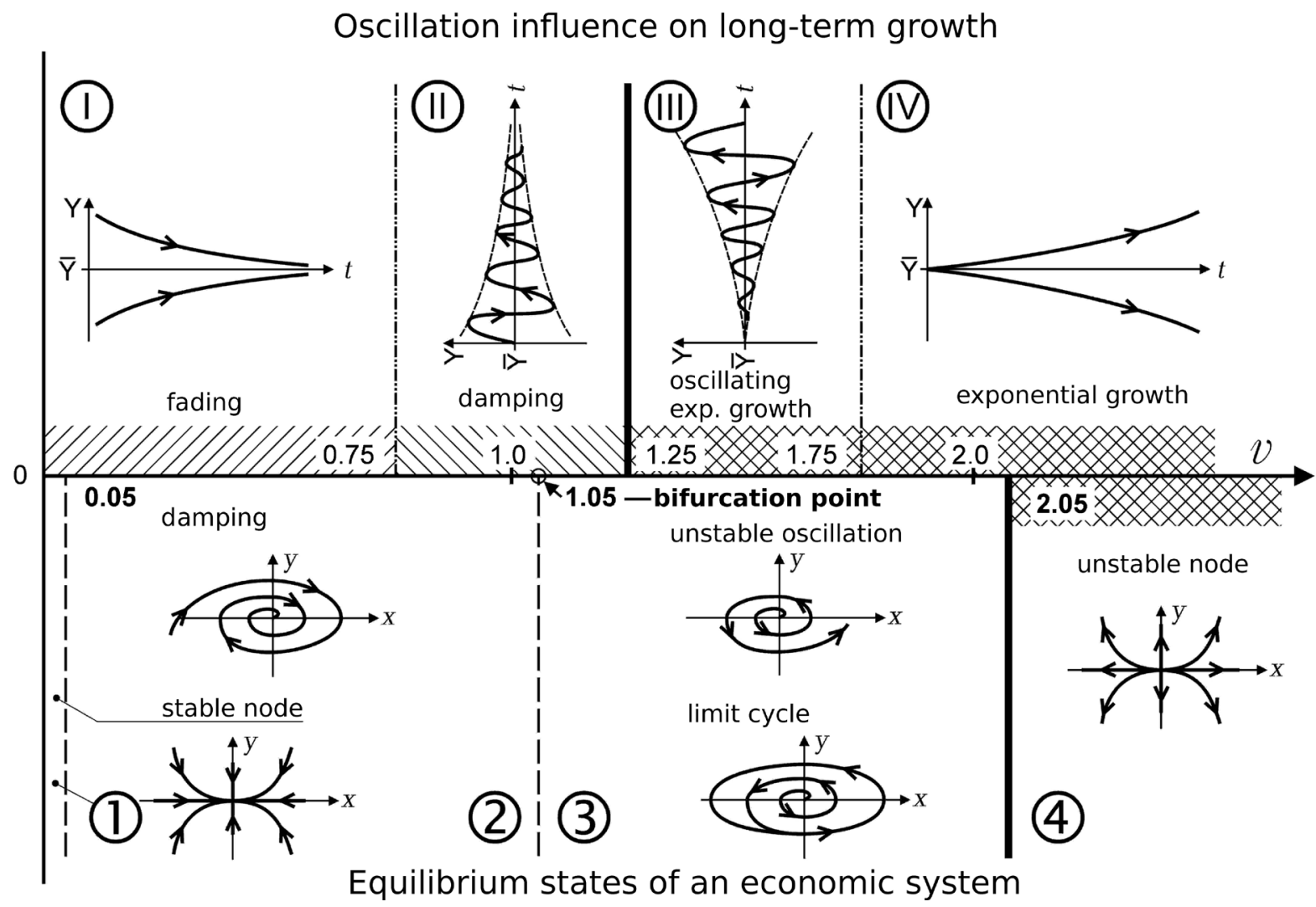

Figure 4. Phase portrait characterizing the zone of stability of dynamic economic system.

describes the real process of economic development. For a more detailed study of economic system behavior it is required to describe a random nature of the exogenous impulse that caused crisis and recession. This means to solve stochastic differential Equation (21). Then chaotic dynamics of the economic system will be described in terms of attractors.

\section{Verification of the Macroeconomic Dynamics Equation and Long-Term Forecasting on the Example of the US}

Below are the results of computer modeling of US macroeconomic dynamics by numerical solution of differential equations describing the trend trajectory of economic development (19) and cyclic fluctuations (21), followed by a superposition of the solutions. Verification of mathematical model (19)-(21) is carried out on the example of economic development in the US during the fifth Kondratieff cycle from 1983 to 2010 . The model is used to forecast the economic development of the United States till 2050.

First, one must identify the right sides of equations (19) and (21) i.e. functions $F_{1}(t)$ и $F_{2}(t)$. The latter, as it can be seen from equations (19) and (21), depends on the autonomous investment $A(t)$ and the production of capital $K(t)$ and its rates. Therefore functional dependence of the basic movements of physical capital $K(t)$ is needed. Accumulation of fixed capital is stable enough and, as was shown by E. Hansen, its dynamics has a form of S-shaped logistic 

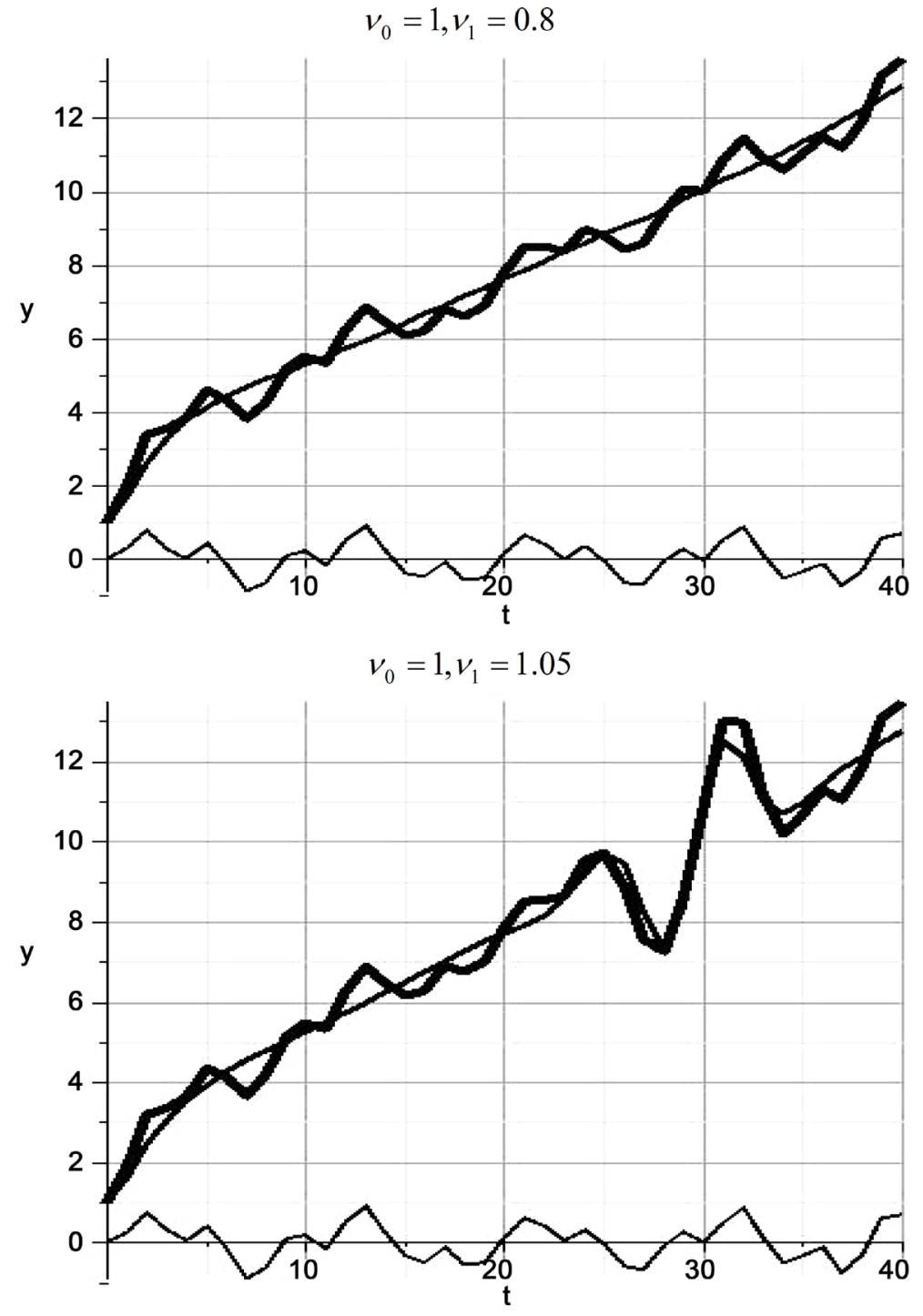

$v_{0}=1, v_{1}=1.1$

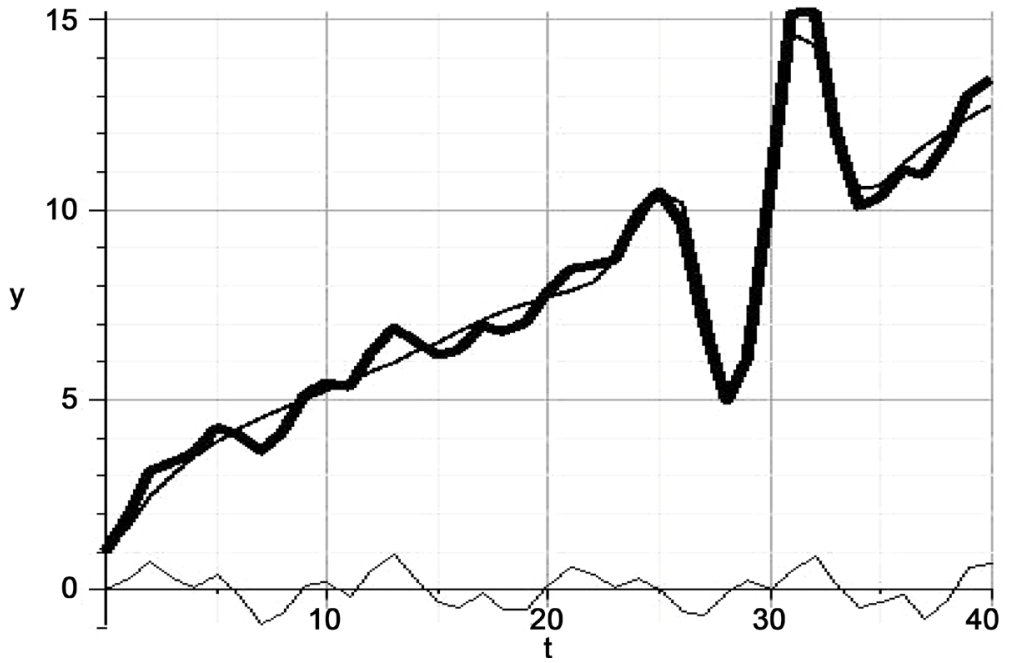

Figure 5. Simulations of the macroeconomic dynamics equations: trend and cyclical components are represented by lines of medium thickness, yield is given by thick lines. 
curve [15]. Long-term economic growth has the same form within a large Kondratieff cycle, which was clearly demonstrated in the fundamental work of Hirooka [16]. This is not surprising because of the ratio of physical capital to yield in the long-term is almost constant. Following up the above considerations it is natural to express a capital in the following form:

$$
\begin{aligned}
K & =\bar{K}(t)+\varphi^{*}(t) \\
& =\frac{K_{0}\left(1+k_{1}\right)}{1+k_{1} \exp \left[-\theta\left(t-T_{0}\right)\right]}+q_{1}\left[\sin \omega_{1}\left(t-T_{0}\right)+\frac{q_{2}}{q_{1}} \sin \omega_{2}\left(t-T_{0}\right)\right] .
\end{aligned}
$$

Here the first term describes the trend trajectory of productive capital, which is expressed by the logistic function, and the second describes the cyclical fluctuations, describing the Kitchin $\left(q_{1}, \omega_{1}\right)$ and Juglar $\left(q_{2}, \omega_{2}\right)$ cycles, $\omega_{1}, \omega_{2}$-frequencies.

Knowing $K(t)$ we can determine the investments:

$$
A=\frac{\mathrm{d} K}{\mathrm{~d} t}+\mu K=\frac{\mathrm{d} \bar{K}}{\mathrm{~d} t}+\mu \bar{K}+\frac{\mathrm{d} \varphi^{*}}{\mathrm{~d} t}+\mu \varphi^{*},
$$

where $\mu$ is the rate of disposal of fixed assets.

Using relationships (25) and (26) we obtain the functional expression for the right sides of equations (19) and (21):

$$
\begin{aligned}
& F_{1}(t)=\lambda K_{0}\left(1+k_{1}\right) \frac{\exp \left[-\theta\left(t-T_{0}\right)\right]}{1+k_{1} \exp \left[-\theta\left(t-T_{0}\right)\right]}\left\{æ \mu \exp \left[\theta\left(t-T_{0}\right)\right]\right. \\
& \left.+\frac{[\mu+\mathfrak{x}+(1-s) i] k_{1} \theta}{1+k_{1} \exp \left[-\theta\left(t-T_{0}\right)\right]}+\frac{k_{1} \theta^{2}\left\{k_{1} \exp \left[-\theta\left(t-T_{0}\right)\right]-1\right\}}{\left\{1+k_{1} \exp \left[-\theta\left(t-T_{0}\right)\right]\right\}^{2}}\right\} ; \\
& F_{2}(t)=q_{1} \lambda\left\{(\mu+æ)\left[\omega_{1} \cos v_{1}\left(t-T_{0}\right)+\omega_{2} \frac{q_{2}}{q_{1}} \cos \omega_{2}\left(t-T_{0}\right)\right]-\omega_{1}^{2} \sin \omega_{1}^{2}\left(t-T_{0}\right)\right. \\
& \left.-\omega_{2}^{2} \frac{q_{2}}{q_{1}} \sin \omega_{2}\left(t-T_{0}\right)+æ \mu\left[\sin \omega_{1}\left(t-T_{0}\right)+\frac{q_{2}}{q_{1}} \sin \omega_{2}\left(t-T_{0}\right)\right]\right\} .
\end{aligned}
$$

The next step is the calibration of the basic production capital model (25). The model contains 6 parameters: $k_{1}, \theta, q_{1}, \omega_{1}, q_{2}, \omega_{2}$. The initial value of capital $\left(K_{0}\right)$ corresponds to the actual amount of capital in $1983\left(T_{0}\right)$, the initial year of the fifth Kondratieff cycle (1982-2017), which we have found in the national accounts of the UN [17]. The maximum value of fixed capital corresponding to the actual amount of capital in 2008 can be determined at the level of $0.9 K_{m}\left(K_{m}\right.$ is the value of saturation). Hence we obtain $K_{2008}=0.9 K_{0}\left(1+k_{1}\right)$. Therefore, $k_{1}=\frac{K_{2008}}{0.9 K_{0}}-1$. Other parameters $\left(\theta, q_{1}, \omega_{1}, q_{2}, \omega_{2}\right)$ are defined as follows. First, we find the parameter $\theta$ describing the trend component:

$$
\bar{K}(t)=\frac{K_{0}\left(1+k_{1}\right)}{1+k_{1} \exp \left[-\theta\left(t-T_{0}\right)\right]} .
$$


Since both $K_{0}$ and $k_{1}$ are known and present in statistics, the parameter $\theta$ can be easily found by least squares method using all the available sample of the actual values of $K_{i}$ in a given period of time (1982-2010). Trend growth of physical capital derived from the approximating Formula (29) is shown in Figure 6. As it can be seen, the approximation is sufficiently good.

To determine the oscillation controlling parameters $q_{1}, \omega_{1}, q_{2}, \omega_{2}$ in the model for capital (25), one must use the investment Equation (26), which with a specific model of capital movements (25) becomes:

$$
\begin{aligned}
A= & \frac{K_{0}\left(1+k_{1}\right)}{1+k_{1} \exp \left[-\theta\left(t-T_{0}\right)\right]}\left\{\mu+\frac{k_{1} \theta \exp \left[-\theta\left(t-T_{0}\right)\right]}{1+k_{1} \exp \left[-\theta\left(t-T_{0}\right)\right]}\right\}+q_{1}\left[\omega_{1} \cos \omega_{1}\left(t-T_{0}\right)\right. \\
& \left.+\omega_{2} \frac{q_{2}}{q_{1}} \cos \omega_{2}\left(t-T_{0}\right)\right]+\mu q_{1}\left[\sin \omega_{1}\left(t-T_{0}\right)-\frac{q_{2}}{q_{1}} \sin \omega_{2}\left(t-T_{0}\right)\right] .
\end{aligned}
$$

The actual values of autonomous investment $A$ are in the same UN database [17], they are shown in Figure 7. The important thing is that in stand-alone investments there are more prominent oscillatory deviations from the trend component and therefore Equation (30) is the best way to find the parameters $q_{1}, \omega_{1}, q_{2}, \omega_{2}$.

In Equation (30) the rate of disposal of fixed capital $\mu$ increases with time due to constant technical progress and it can be approximated by a linear relationship:

$$
\mu=\mu_{0}+\mu_{1}\left(t-T_{0}\right) .
$$
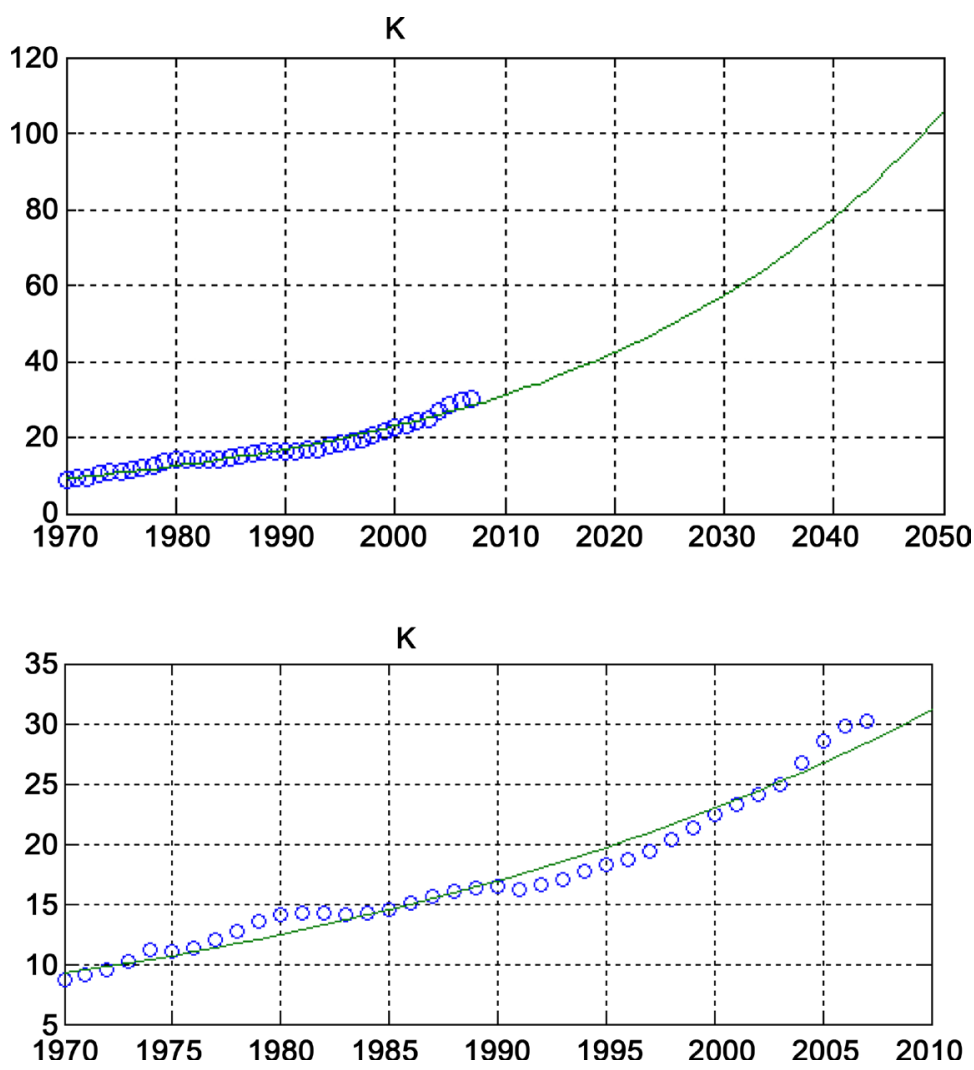

Figure 6. Approximation and extrapolation of physical capital. 
Constants $\mu_{0}$ and $\mu_{1}$ are easy to find by the least squares method using a statistics for the period 1982-2010 [17]. For the US economy, we have found that $\mu \cong 0.033$ and $\mu_{1} \cong 1.1 \times 10^{-4}$ i.e. this approximately corresponds to annual $3.3 \%$.

The parameters of approximating functions (25) and (30) for the main production of capital $K(t)$ and autonomous investment $A(t)$ are defined by least squares method using statistics databases:

$$
\begin{aligned}
& q_{1} \cong 0.075 ; \omega_{1} \cong 0.66 ; T_{1} \cong 9.5 \text { years; } T_{0}^{*} \cong 1998 ; \\
& q_{2} \cong 0.225 ; \omega_{2} \cong 0.28 ; T_{2} \cong 22.4 \text { years; } T_{0}^{* *} \cong 2002 ; \\
& K_{0} \cong 10.77 \text { trillion dollars; } k_{1} \cong 3.5 ; \theta \cong 0.09 ; T_{0} \cong 1982 .
\end{aligned}
$$

Curve $A(t)$, which is calculated in (30) shown in Figure 7. The US economy during 1982-2010 was characterized by Juglar cycles with period of 9.5 years, and Kuznets cycles with period of 22.4 years, the amplitude of Kuznets cycles is 3 times as high as the amplitude of Juglar cycles.

Thus, having the specific values of all parameters, we can calculate the right side of (27) and (28). The following pair $\lambda=1.4$ and $\mathfrak{x}=1.3$ in Equations ((19) and (21)) provides the best approximation for the US GDP over the period from 1982 to 2010 . We have also found the average savings rate in this period $s=$ 0.184 .

Figure 8 shows the results of computer simulation for differential Equations ((19) and (21)) with given values of parameters (32). The maximum of deviation is not more than $7 \%$. Extremely important is the fact that the model captures and reflects the crisis recessions of 1990-1991 and 2000-2001, as it is evident

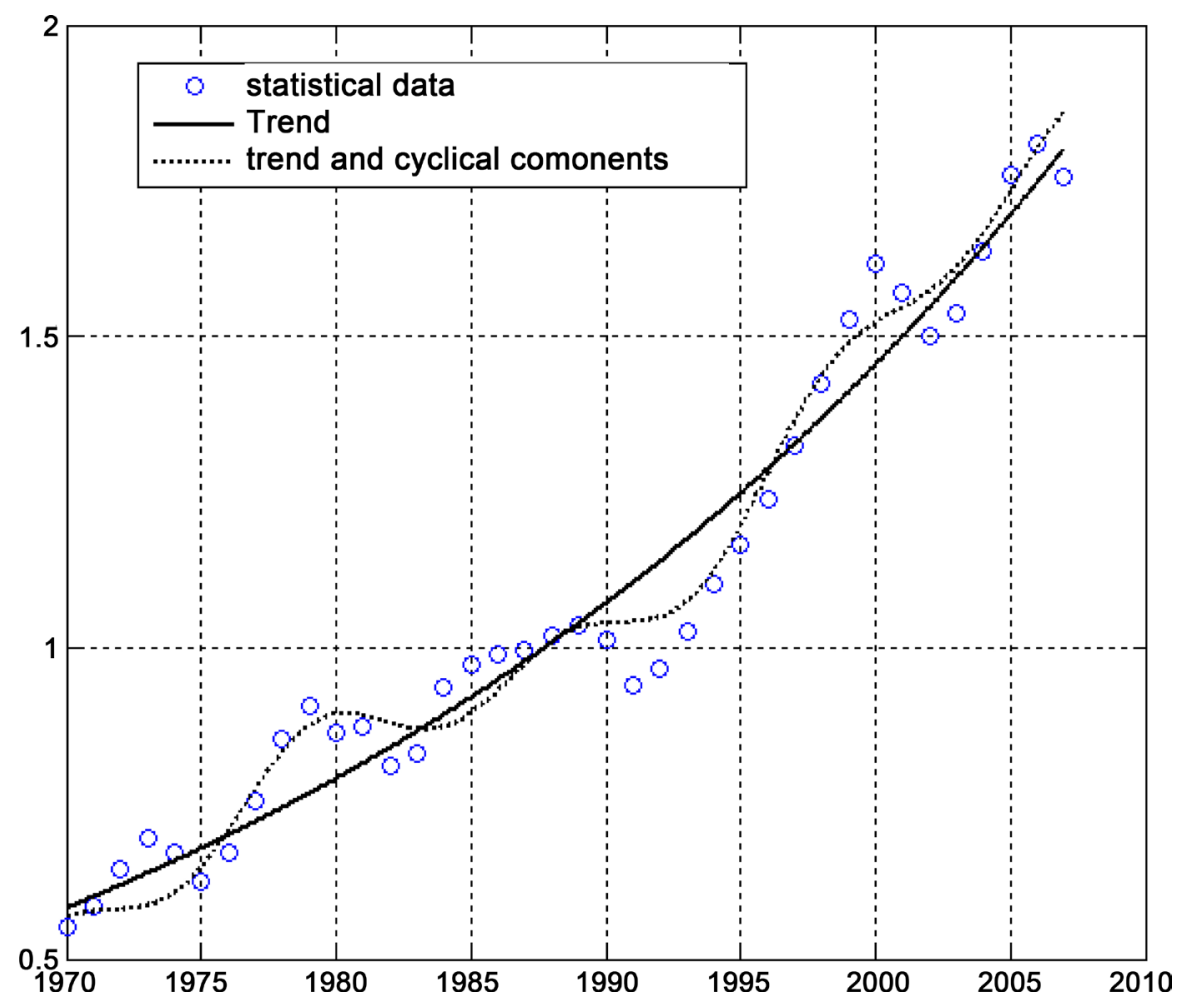

Figure 7. Data for $A$, trend component and the model (the sum of trend and cycles). 


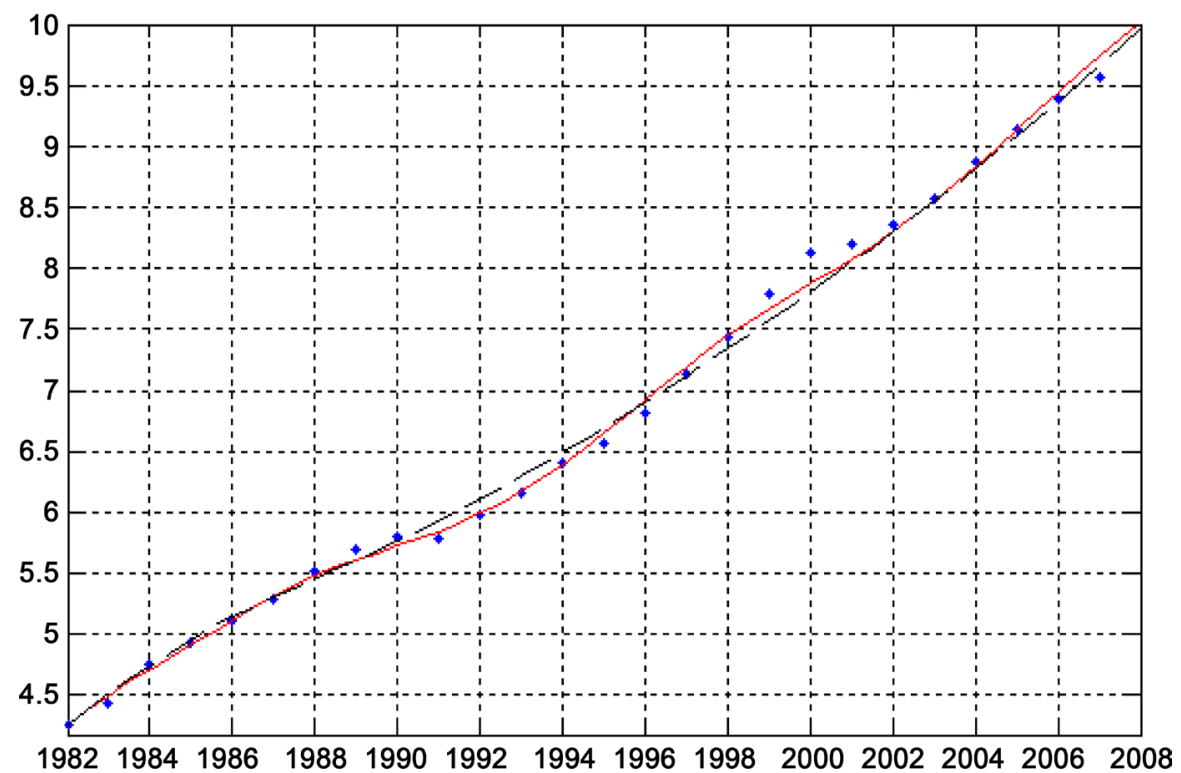

Figure 8. GDP fit with sum of solutions of differential equations $\lambda=1.4$ and $æ=1.3$ (larger scale) dotted line is the trend, the solid is the sum of solutions.

from Figure 8. Hence a mathematical model that takes into account the effect of cyclical fluctuations on the formation of long-term growth trajectories gives good results.

In conclusion, we use the model to forecast the dynamics of the US economy for the period corresponding to the duration of the upcoming sixth Kondratieff cycle (2018-2050). The model parameters are quite stable in the long run and therefore the numerical values (32) obtained during calibration of the model in the period from 1982 to 2010 can be used in the forecasting process. Therefore it is sufficient to determine the initial and final values of capital $K_{0}$ and $K_{0}\left(1+k_{1}\right)$. In the year of recovery (2018) at the beginning of an upward wave of the sixth Kondratieff cycle $K_{0}$ will be almost identical with the volume of the pre-crisis year, i.e. $K_{2018} \cong K_{2008}$. To determine the final volume of primary production capital we will use following considerations arising from the analysis of trends in long-term economic development.

In the long run there is a stable capital-output ratio $(K / Y)$, which is also expressed in empirical Kaldor's law [18]: $K=c_{K} Y \quad\left(c_{K}=\right.$ const $)$. Friedman shows that in the long run, permanent consumption is directly proportional to permanent income [9]: $C=c_{Y} Y$. Consequently, $K \sim C$. This means that if you know the expected growth in consumption, it is easy to determine the expected growth in basic industrial capital.

R. Hall argues that if consumer' expectations are rational then consumption follows the trajectory of a random walk [19]. This means that consumption $C$ is not likely to be out of the region $C^{e} \leq 3 \sigma_{C} \sqrt{t} \quad$ ( $\sigma_{C}$ is standard deviation of $C$ ). This follows from the properties of Gaussian random walks called the Wiener process [20]. Thus, it can be taken that $C_{\max }^{e}=3 \sigma_{C} \sqrt{T-T_{0}}$. This formula is valid for $\ln \left(T-T_{0}\right)>0$, which implies that $T-T_{0}>e$. Therefore, we can take 
$\left(C_{\max }^{e}\right)_{0}=3 \sigma_{C} \sqrt{3}$. To estimate growth in consumption during the period of time $T-T_{0}$ one can suggest the following simple equation:

$$
\frac{C_{\max }^{e}}{\left(C_{\max }^{e}\right)_{0}}=\sqrt{\frac{T-T_{0}}{3}}
$$

Therefore,

$$
\frac{K_{\max }}{K_{0}}=\sqrt{\frac{T-T_{0}}{3}} .
$$

Substituting $T=2050$ and $T_{0}=2010$ in Equation (34) we get: $K_{\max } \cong 3.6 K_{0}$. As $K_{\max }=K_{0}\left(1+k_{1}\right)$ it implies that $k_{1}=2.6$.

Trajectory of the US GDP till 2050 calculated with the model (19) and (21) is shown in Figure 9. Simulation pretty well describes the changes in economy during the long Kondratieff wave including a sharp decrease in 2008-2009 and 2038-2039 leading to a crisis and recession. These cyclical crises accompanied by depressions are seen especially clearly. The depth of the crisis depends on $v_{1}$ which reflects the speculative activity and $v_{0}$ this is a normal business activity. The forecast also shows that by 2050 the volume of US GDP will reach about 36 trillion dollars in constant 2000 prices, which almost coincides with the prediction obtained by Goldman Sachs analysts [21].

The suggested mathematical model of long-term economic growth containing two (cyclical and trend) components provides a good description of real macroeconomic dynamics both qualitatively and quantitatively. The model also allows to estimate timings of crises, which can be seen in Figure 9. Still the question of special interest is the following: is it possible to more accurately predict the crisis time?

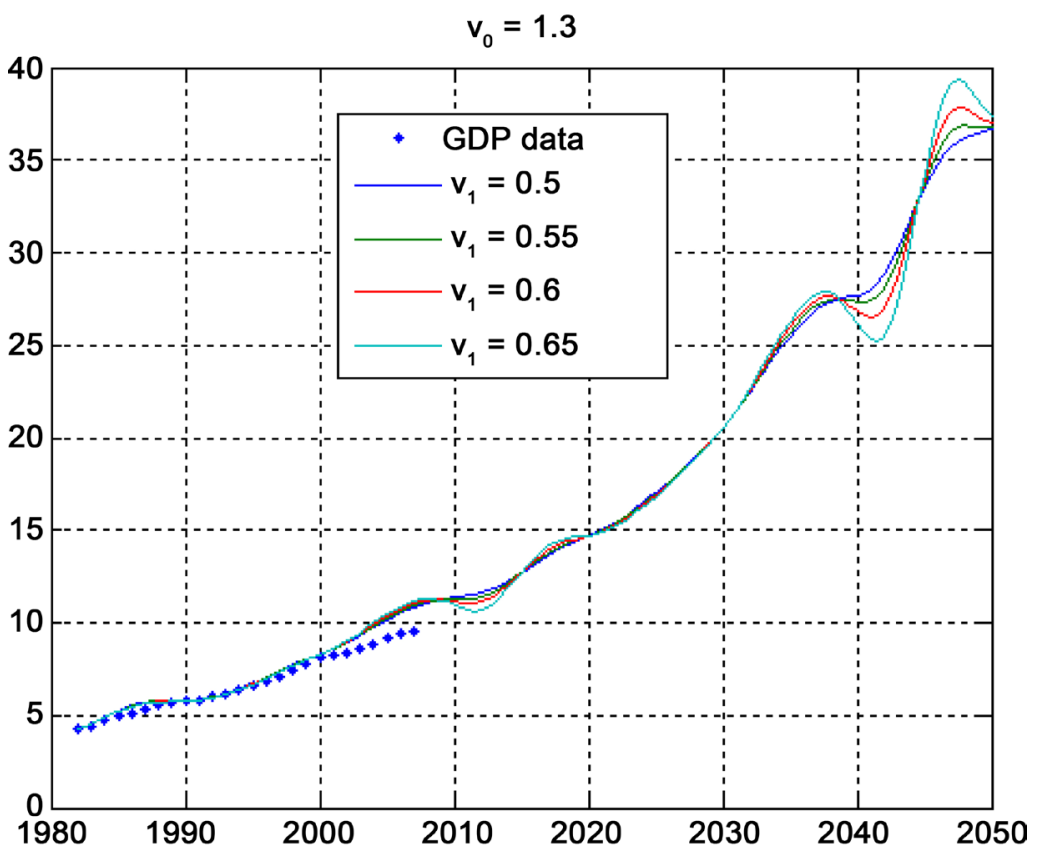

Figure 9. Forecast of US GDP. 


\section{Burst of the Gold and Oil Bubbles as a Predictor of the Global Economic and Financial Crisis}

Didier Sornette, Anders Johansen and their colleagues (e.g., [22]) have demonstrated that accelerating log-periodic oscillations superimposed over an explosive growth trend that is described with a power-law function with a singularity (or quasi-singularity) in a finite moment of time $t_{C}$,

$$
x(t)=a+b\left(t_{C}-t\right)^{\beta}+c\left(t_{C}-t\right)^{\beta} \cos \left[\omega \ln \left(t_{C}-t\right)+\phi\right],
$$

are observed in situations leading to crashes and catastrophes, and can be treated as their predictors. In our paper [23] we show that the hyperbolic growth in the global prices of highly liquid commodities (such as gold and oil) can be treated as a predictor of a deep crisis in the world economy, and we have proposed an algorithm for estimating the critical time (the time of the crisis) based on approximation of current prices dynamics with a function of type (34). Energy is a major productive resource. The structure and the level of energy consumption describe the state of world and national economies, as well as the level and quality of life. There is also a close connection between energy consumption and economic growth. Currently the dominant energy source is oil, but the era of gas is approaching. Marchetti and Nakicenovic were the first who drew attention to the cyclic increases of prices of the dominant energy sources with a period of Kondratieff cycles [24]. These price increases usually last for about 10 years and lead to significant shift in structure of energy consumption. We have shown that these increases of prices are predictors of the global crises in the world economic and financial system. Indeed when the global economy is in the upswing phase of Kondratieff wave, the global market expands and oil prices are stably low and are determined by the costs of production and transportation in agreement with theory of Kondratieff waves. But as soon as there is a significant world market downturn in a downswing phase of Kondratieff wave, capital begins to rapidly flow into oil and gold which are commodities with absolute (or almost absolute) liquidity. All this causes increase in oil and gold prices, as is shown in Figure 10 and Figure 11.

Figure 10 demonstrates that oil price rose to $\$ 50$ per barrel immediately after the oil shock in the early 1970's and then up to $\$ 95$ per barrel by 1979 . That was the start of the economic crisis of 1980-1982. Then the oil price declined and stabilized at the level of $\$ 25$ - 35 per barrel in the mid-1980s. In 2003 a new rise began. In 2004-2006 the world economy entered the downswing phase of the fifth Kondratieff wave. This phase is expected to last until 2017-2018 (see, e.g., [25]). In 2006-2008 oil prices increased dramatically. Within eighteen months they rose from $\$ 60$ to $\$ 145$ per barrel. That marked the start of global economic crisis when the oil price fell down till $\$ 30$ per barrel. Afterwards the prices returned to a stable level of \$ 70 - 85 per barrel which was considered comfortable for both producers and consumers. However, by March 2011, oil prices rose to $\$ 110$ - 120 per barrel. This dynamics of oil prices could not be due to fundamental factors but could be 


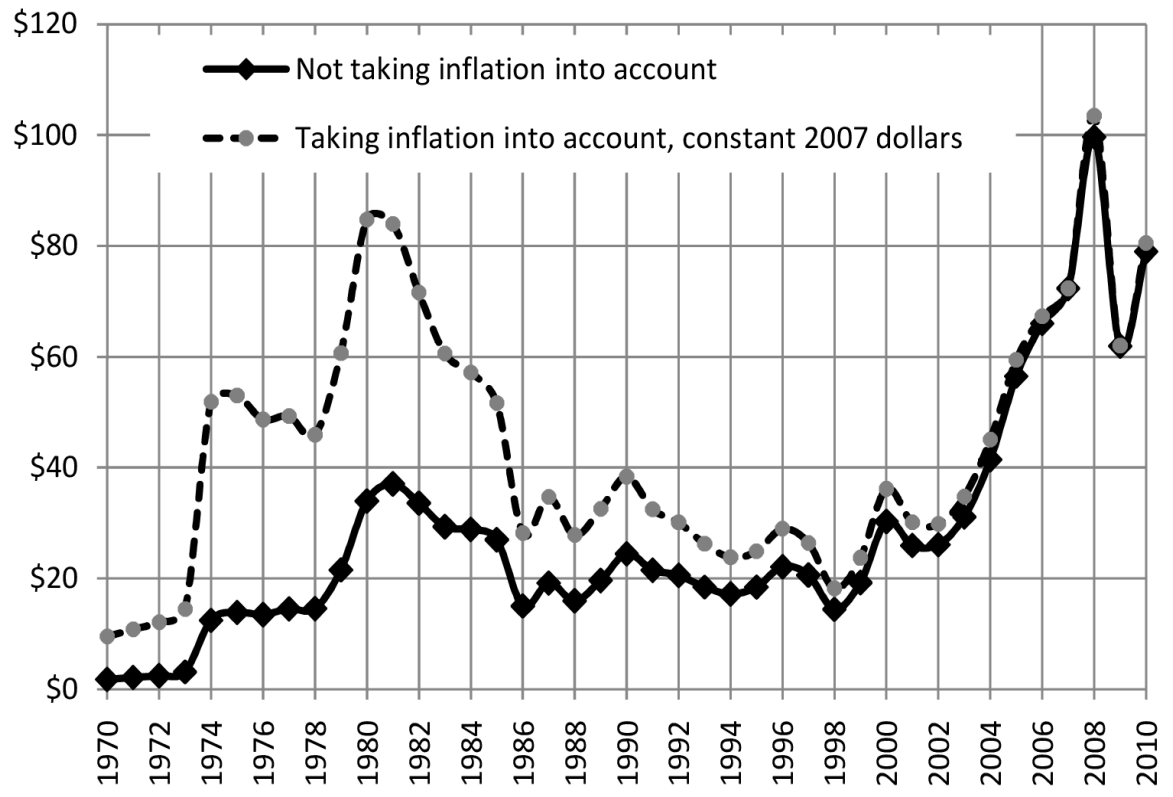

Sources: database US Energy Information Administration. URL:

http://www.eia.doe.gov/dnav/pet/pet_pri_spt_s1_a.htm; World Development Indicators Online (Washington, DC: World Bank, 2010), URL: http://data.worldbank.org/data-catalog/world-development-indicators (US inflation).

Figure 10. Oil prices at US markets, 1970-2010.

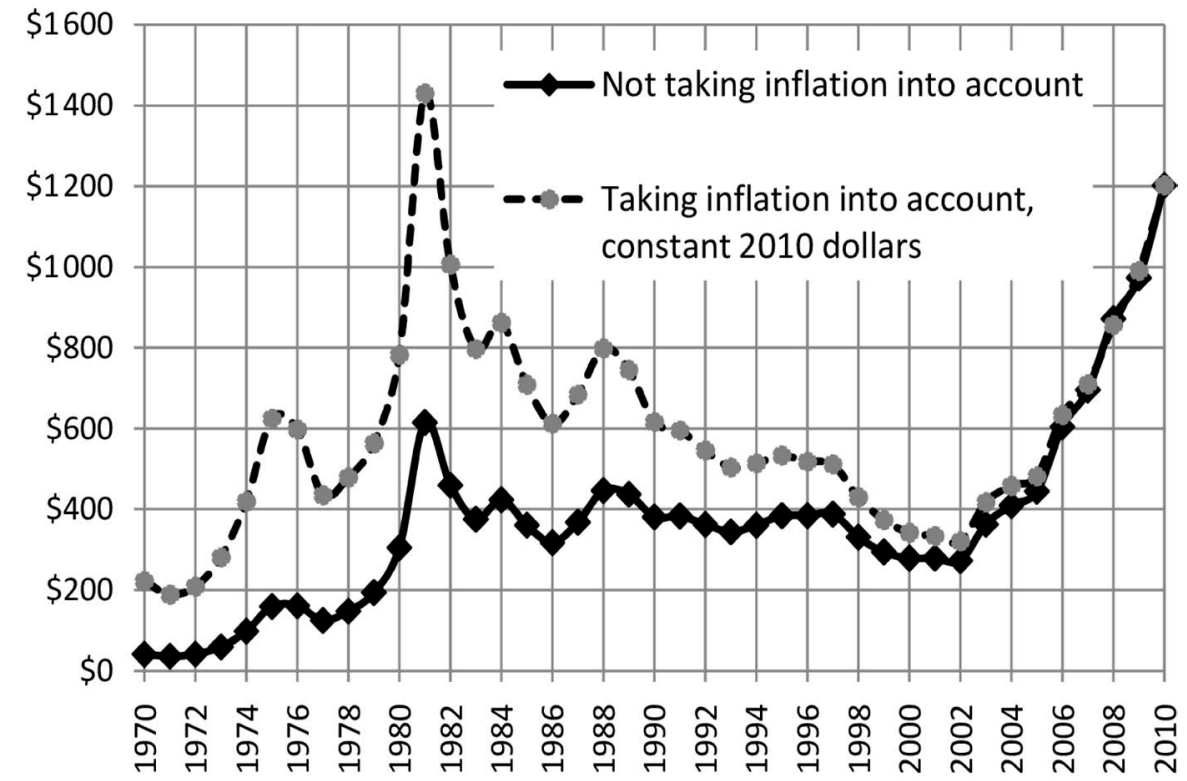

Note: yearly London fixing averages. Sources: World Gold Council database. URL:

https://www.statista.com/statistics/268027/change-in-gold-price-since-1990/ (gold prices for 1970-2009); USA Gold Reference Library database. URL: http://www.usagold.com/reference/prices/history.html (average price for January 4-November 12, 2010); World Development Indicators Online (Washington, DC: World Bank, 2010), URL: http://data.worldbank.org/data-catalog/world-development-indicators (data on USA inflation).

Figure 11. Gold prices 1970-2010, US dollars per troy ounce, London price fix.

due to speculative factors. We supposed the level of 2008 (\$130 - 140 per barrel) was critical and may have led to the next wave of the world economic crisis. 
Actual oil prices can be approximated with the following function:

$$
p(t) \cong p_{0}+p_{1}\left(t_{C}-t\right)^{\beta}\left\{1+p_{2} \cos \left[\omega \ln \left(t_{C}-t\right)+\phi\right]\right\} .
$$

Figure 12 and Figure 13 display actual data for oil and gold prices and their approximations with a function of type (35). It is evident that the hyperbolic trend and log-periodic oscillations both allows to build accurate estimation of crisis recession start. Method of calculation is described in detail in our paper [23].

The following parameters of the approximating function (35) were estimated with least squares method based on the available statistics:

1) for oil prices: $p_{0}^{(o)}=66.9 ; p_{1}^{(o)}=22.84 ; p_{2}^{(o)}=0.0557 ; \quad \beta^{(o)}=0.915$; $\omega^{(o)}=22.097 ; \phi^{(o)}=0.471 ; t_{C}^{(o)}=$ August 31,$2008 ;$

2) for gold prices: $p_{0}^{(g)}=1220.4 ; p_{1}^{(g)}=-570.35 ; \quad p_{2}^{(g)}=0.036$; $\beta^{(g)}=0.266 ; \omega^{(g)}=15.86 ; \phi^{(g)}=-34.76 ; t_{C}^{(g)}=$ September 14, 2011.

The model (35) was to have predicted in 2008 the beginning of the oil price collapse for about 80 days in advance if had been applied.

Let us take a look at gold prices. In early 2011 they were still rising. Market players found gold as the most reliable replacement of national currencies and companies stocks. Therefore, there was a big increase of investment in gold and we treated it like a predictor of the second wave of the crisis. Applying model (35) to gold prices gave singularity point in August 2011. We forecasted that the latter may have precipitated the second crisis wave. The actual events confirmed our forecast [26].

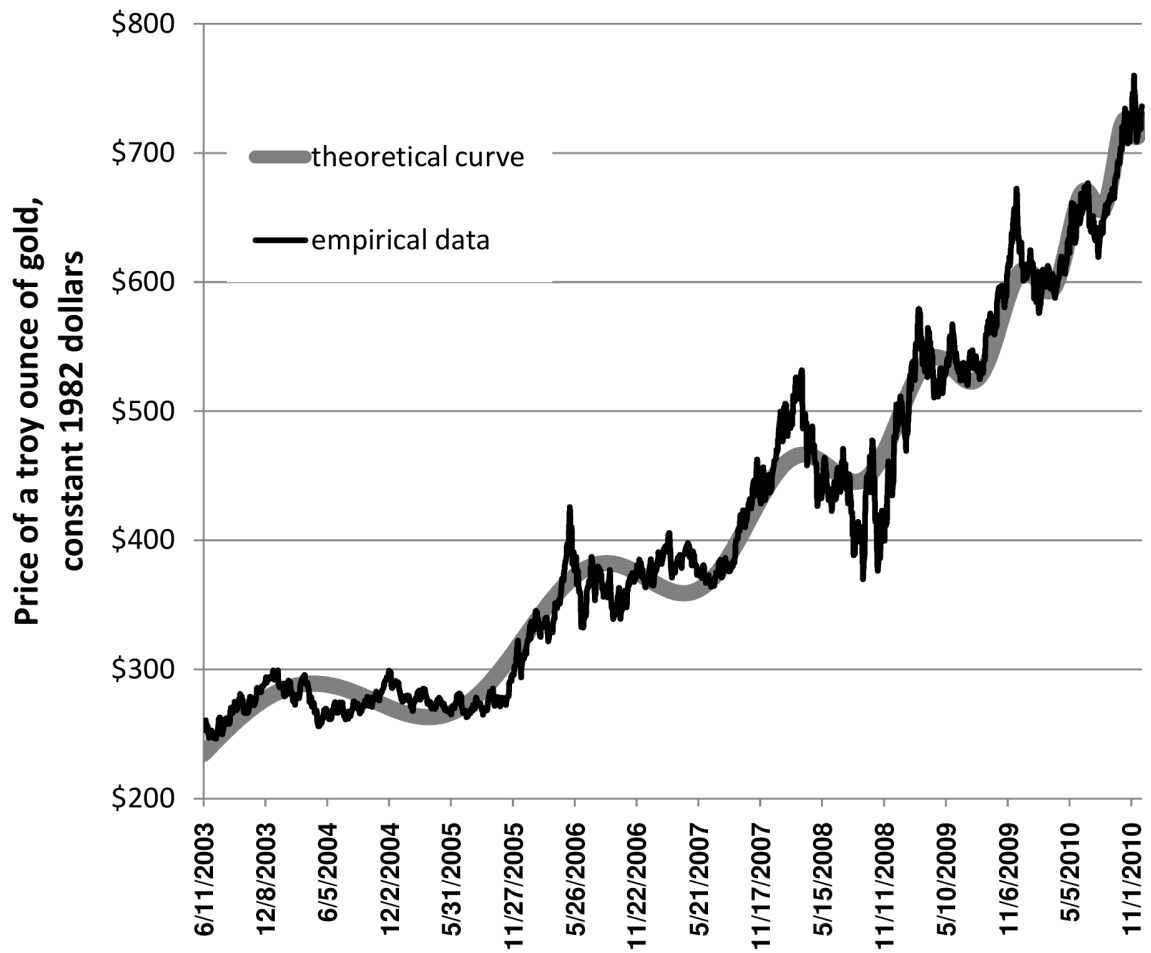

Figure 12. Log-periodic oscillations in the dynamics of world gold prices, constant 1982 dollars inflation adjusted. June 11, 2003-December 2, 2010 (gray markers correspond to the empirical data, the thick smooth black curve generated by Equation (35)). 


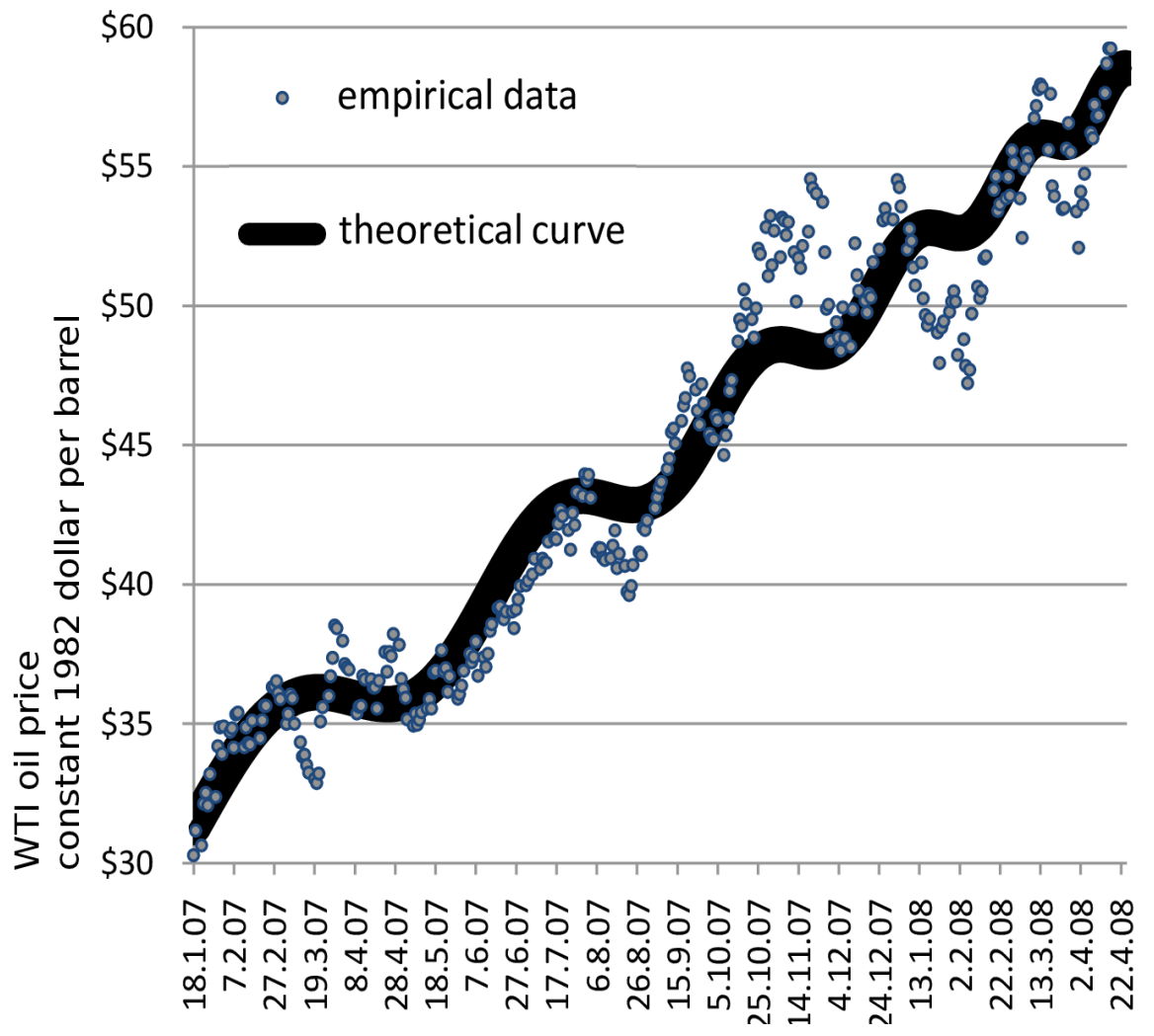

Figure 13. Log-periodic oscillations in the dynamics of world oil prices in constant 1982 dollars, inflation adjusted, 2007-2008 (grey markers correspond to the empirical data, the thick smooth black curve generated by Equation (35)).

Thus oil and gold prices are predictors of global cyclical crises associated with large Kondratieff waves of global market conditions with period of 30 - 40 years. Such global cyclical crises include, for example, the global economic crisis of the 1970s, as well as the current crisis started in 2008. As to the intermediate recessions that happen every 8 - 10 years they are associated with mid-term Juglar cycle. Within the Juglar cycle one can observe oscillations of investments into fixed capital. In fact this is a tool for predicting local economic crises such as the dot.com bubble burst in 2001 in the USA.

Today the next economic upswing is associated with the broad adoption of innovations based on nano- and biotechnologies, genetic engineering and regeneration of human organs (see, e.g., [25]). If those technologies are overestimated the next crisis can occur in the decade. Consequently the investments and technological innovations are to be attentively monitored during the forthcoming years. The mechanism for falling into the crisis can be suggested as follows: investments in new technologies increase much faster than technological progress does. In this case efficiency of investment decreases to its minimum level and investments do not return. This leads to a crisis. On the other hand, the trigger for most of the economic crises of recent decades was burst of one of "financial bubbles". For example, US economy recession that started in 2001 was initiated by stock market collapse of late 2000 . 


\section{References}

[1] Allen, R.G.D. (1960) Mathematical Economics. Macmillan and Co. Ltd., London, St. Martin's Press, New York.

[2] Solow, R. (1956) A Contribution to the Theory of Economic Growth. Quarterly Journal of Economics, 70, 65-94. https://doi.org/10.2307/1884513

[3] Schumpeter, J.A. (1934) The Theory of Economic Development. Harvard University Press, Cambridge.

[4] Schumpeter, J.A. (1939) Business Cycles. McGraw-Hill, New York.

[5] Kydland, F. and Prescott, E. (1982) Time to Build and Aggregate Fluctuations. Econometrica, 50, 1345-1370. https://doi.org/10.2307/1913386

[6] Akaev, A.A. (2007) Derivation of the General Macroeconomic Dynamics Equation Describing the Joint Interaction of Long-Term Growth and Business Cycles. Doklady Mathematics, 76, 879-881. https://doi.org/10.1134/S1064562407060191

[7] Stoleru, L. (1967) L'equilibre et la croissance economiques: Principes de macroeconomie. Dunod, Paris.

[8] Okun, A.M. (1970) The Political Economy of Prosperity. Norton, New York.

[9] Sachs, J. and Larrian, F. (1993) Macroeconomics in the Global Economy. Prentice Hall, New York.

[10] Bogolyubov, N.N. and Mitropol'skii, Yu.A. (1962) Asymptotic Methods in the Theory on Nonlinear Oscillations. Gordon \& Breach, New York.

[11] Akaev, A.A. (2008) Influence of Business Cycles on Long-Term Economic Growth. Doklady Mathematics, 78, 1-5. https://doi.org/10.1134/S106456240804039X

[12] Pantin, V.I. and Lapkin, V.V. (2006) Philosophy of Historical Forecasting: Rhythms of History and Perspectives of World Development. Fenix +, Dubna.

[13] Akaev, A.A. (2008) An Analysis of Solutions of General Equation of Macroeconomic Dynamics. Economics and Mathematical Methods, 44, c62-c78.

[14] Akaev, A.A., Galileev, M.M. and Mikhailushkin, A.I. (2011) Computer Analysis of the Model of Long-Term Economic Development. Future Projects and Risks. M: KRASAND, 130-137.

[15] Hansen, A. (1951) Business Cycles and National Income. W. W. Norten, New York.

[16] Hirooka, M. (2006) Innovation Dynamism and Economic Growth. A Nonlinear Perspective. Edward Elgar, Cheltenham, Northampton.

[17] United Nations Database.

[18] Kaldor, N. (1961) Capital Accumulation and Economic Growth. The Theory of Economic Growth. St. Martin's Press, New York, 177-222.

https://doi.org/10.1007/978-1-349-08452-4_10

[19] Hall, R.E. (1978) Stohastic Implications of the Life Cycle-Permanent Income Hypothesis: Theory and Evidence. Journal of Political Economy, 86, 971-987. https://doi.org/10.1086/260724

[20] Artamonov, N.V. (2008) Theory of Random Processes. M: "MGIMO University" Publishing House.

[21] Wilson, D. and Parashothaman, R. (2003) Dreaming with BRICs: The Path to 2050. Goldman Sachs; New York, Global Economics Paper 99.

[22] Sornette, D. and Johansen, A. (2001) Significance of Log-Periodic Precursors to Financial Crashes. Quantitative Finance, 1, 452-471.

https://doi.org/10.1088/1469-7688/1/4/305 
[23] Akaev, A., Fomin, A., Tsirel, S. and Korotayev, A. (2011) Log-Periodic Oscillation Analysis Forecasts the Burst of the "Gold Bubble" in April-June 2011. Structure \& Dynamics, 5, 3-18.

[24] Marchetti, C. and Naricenovic, N. (1979) The Dynamics of Energy Systems and the Logistic Substitution Model. International Institute for Applied Systems Analysis, Laxenburg.

[25] Korotayev, A. and Tsirel, S. (2010) A Spectral Analysis of World GDP Dynamics: Kondratieff Waves, Kuznets Swings, Juglar and Kitchin Cycles in Global Economic Development, and the 2008-2009 Economic Crisis. Structure and Dynamics, 4, 3-57. http://www.escholarship.org/uc/item/9jv108xp

[26] Akaev, A., Sadovnichy, V. and Korotayev, A. (2012) On the Dynamics of the World Demographic Transition and Financial-Economic Crises Forecasts. The European Physical Journal Special Topics, 205, 355-373.

https://doi.org/10.1140/epjst/e2012-01578-2 